\title{
Developing and Evaluating Novel Treatments for Nonsuicidal Self-Injury Within Swedish Health Care
}

\author{
By Johan Bjureberg
}

\section{ABSTRACT}

Nonsuicidal self-injury is common and associated with subsequent adverse outcomes. Early interventions may prevent suicide among other outcomes. Available treatment options are comprehensive and time-consuming and may not be readily available to everyone in need. Emotion regulation group therapy (ERGT) and emotion regulation individual therapy (ERITA) were designed to address the need of effective short-term, focused, and easily implementable treatments for adults and adolescents with selfinjurious behaviors. A Swedish research program comprising five psychological treatment studies has been launched, among them the development of an online version of ERITA. Results from the first three studies provides promising information about feasibility, acceptability, and utility of ERGT and ERITA. Study IV and Study $\checkmark$ will utilize randomized controlled designs to examine treatment efficacy of online ERITA. The present article reviews and discusses methodological considerations, results, experiences, and implications for future research.

\section{SAMMENDRAG}

Selvskading er hyppig forekommende og har ofte mange uheldige konsekvenser. Tidlig intervensjon er et viktig selvmordsforebyggende tiltak. Eksisterende behandlingsalternativer er som regel omfattende og tidkrevende og er ikke alltid lett tilgjengelige for dem som har behov for behandling. Emosjonsreguleringsterapi i gruppe (ERGT) og som individualterapi (ERITA) er utviklet for å imøtekomme behovet for effektiv kortvarig og fokusert behandling som er enkel å implementer for voksne og ungdom med selvskadende atferd. Et svensk forskningsprogram bestående av fem psykologiske behandlingsstudier har blitt lansert, blant dem utviklingen av en online versjon av ERITA. Resultater fra de tre første studiene gir lovende informasjon om gjennomførbarhet, akseptabilitet og nytteverdi av ERGT og ERITA. Den fjerde og femte studien vil bruke randomisert kontrollerte design for å undersøke behandlingseffekten av online ERITA. I denne artikkelen gjennomgås og diskuteres metodiske betraktninger, resultater, erfaringer med disse behandlingsprogrammene og implikasjoner for fremtidig forskning.

\begin{abstract}
Nonsuicidal Self-Injury (NSSI)
NSSI refers to intentional and self-inflicted destruction of body tissue without suicidal intent and affects approximately $17-18 \%$ of adolescents worldwide (Swannell et al., 2014). NSSI is associated with a range of adverse outcomes such as alcohol misuse, psychiatric inpatient care (Bjureberg et al., 2018a; Ohlis et al., 2020), and suicide attempts (Asarnow et al., 2011). However, when comparing adolescents engaging in NSSI with adolescents engaging in both NSSI and suicidal behavior, the latter group has even greater risks and are additionally vulnerable to subsequent drug misuse disorder, occupational problems, and both non-violent and violent crime (Bjureberg et al., 2018a). Hence, providing care to individuals with NSSI has the potential to not only prevent suicide but also a range of other adverse outcomes.
\end{abstract}

\section{Treatments for NSSI}

To date, treatments specifically designed to target NSSI are scarce (Iyengar et al., 2018; Ougrin et al., 2015). Recently, two independent randomized controlled trials (RCT) demonstrated efficacy in treating self-injury with dialectical behavioral therapy (McCauley et al., 2018; Mehlum et al., 2014; 2016) and 
consequently DBT is considered to be the first and only evidence-based treatment for highly suicidal self-injuring adolescents (Asarnow \& Mehlum, 2019). However, DBT does not only aim at reducing NSSI-frequency, but also other symptoms of borderline personality disorder (BPD), and the treatment is comprehensive and time-consuming (including both weekly individual therapy sessions and skills training in group). Thus, DBT may not be readily available to everyone that engages in NSSI. A consequence of the lack of early specific treatment programs for individuals with NSSI is that substantial time may pass between the onset of this risk behavior and enrollment in evidence-based interventions. Hence, effective early and short-term evidence-based treatments for individuals with self-injurious behaviour are urgently needed (Glenn et al., 2019).

\section{Emotion Regulation Group Therapy (ERGT)}

ERGT is an acceptance-based behavioral therapy that was designed to address the need of an effective shortterm, focused, and easily implementable treatment for adults with NSSI. ERGT is delivered over the course of 14 weeks and is administered adjunctive to treatment as usual. ERGT was developed with the expectation that if you teach individuals with NSSI more effective non-avoidant emotion regulation skills, they will cease to harm themselves (Gratz et al., 2019). Such skills include increasing the awareness and acceptance of emotions, the ability to inhibit impulsive behaviors and engage in goal-directed behaviors when experiencing aversive emotions, and strategies to modulate the intensity of emotions. Two RCTs on ERGT for adult women with BPD and self-injurious behaviors have shown significant effects on NSSI, other self-destructive behaviors, and emotion dysregulation, among other outcomes (Gratz \& Gunderson, 2006; Gratz et al., 2014).

\section{Our Research Program}

Our research program involves a series of five consecutive intervention studies, each study designed to answer at set of research questions serving as the foundation for subsequent studies. Our aim is to develop and evaluate novel treatments that can be easily and widely implemented for individuals who engage in NSSI. The project has been supported in part by the National Self-Injury Project, a national government-funded developmental project. In the first study, we evaluated ERGT in a multi-site feasibility trial for adult women with NSSI. Second, we adapted the ERGT-treatment for adolescents and evaluated the treatment (emotion regulation individual therapy for adolescents [ERITA]) in an uncontrolled open trial. Third, in an attempt to increase accessibility to psychological treatment for adolescents with NSSI, we adapted ERITA to an online format and studied it in an uncontrolled open trial. Fourth, we are currently evaluating the efficacy of online ERITA in two ongoing RCTs in Sweden and Denmark. Finally, if online ERITA is efficacious, we are planning a Swedish nationwide implementation study of online ERITA. Below, I briefly summarize Study I to Study III. 


\section{Study I: Feasibility and Utility of ERGT}

Although ERGT had shown promise in university settings, the treatment had never been evaluated in a traditional clinical setting and the extent to which ERGT could be delivered by community clinicians to community patients was not clear. Our aim in Study I was to examine the feasibility and utility of ERGT within Swedish psychiatric health care.

\section{Method}

Study I employed a multi-site uncontrolled open trial design with assessments at pretreatment, posttreatment and 6-month follow-up. A more detailed and comprehensive description of study methods and results may be found elsewhere (Bjureberg, 2018; Sahlin et al., 2017).

\section{Participants}

In total, 95 women (aged 18-49) with repeated NSSI were included at 14 clinics across Sweden. See Table 1 for demographic data.

\section{Instruments}

The Credibility/Expectancy Scales (CES) (Borkovec \& Nau, 1972) were used to assess the perceived credibility of the interventions (range 1-9) and patients' expectancies regarding its benefits (range: 0-100\%). The 16-item Deliberate Self-Harm Inventory (DSHI) (Gratz, 2001) was used to assess NSSI frequency and versatility. Finally the Difficulties in Emotion Regulation Scale (DERS) (Gratz \& Roemer, 2004) was used to assess emotion dysregulation (range 36-180).

\section{Intervention}

We translated and culture-adapted the ERGT manual to Swedish and invited clinics across Sweden to apply for participation in the study. Thirty clinicians from 15 clinics were provided with the ERGT-manual and participated in a three-day workshop delivered by the developers of the treatment (Drs. Gratz and Tull). All therapy sessions were filmed and reviewed to facilitate treatment supervision.

\section{Statistical Analyses}

NSSI frequency was analysed using negative binomial generalized mixed models. The percentage change from baseline to any subsequent time point was utilized as an effect size. This was calculated by exponentiating the estimate for the slope in the generalized mixed model and interpreting the range below 1 as the percentage decrease in NSSI frequency for each 1-unit increase in the predictor. We used McNemar's exact tests to analyse the changes in NSSI abstinence between the assessment points. The remaining continuous outcomes were analysed using linear mixed models. Effect sizes for these outcomes are reported as Cohen's d.

\section{Results}

Session attendance and ratings of treatment credibility and expectancy were satisfactory (see Table 2). At post-treatment, intention-to-treat analysis revealed a significant increase in past 4-month NSSI abstinence $(17.9 \% ; p<.001), 52 \%$ reduction in NSSI frequency (95\% confidence interval $\left.[\mathrm{CI}]=33^{-66}\right)$, as well as significant reductions in NSSI versatility $(d=0.41,95 \% \mathrm{CI}=$ 0.19-0.63), 29\% (95\% CI = 14-41), other self-destructive behaviors, and emotion dysregulation $(d=0.91,95 \% \mathrm{CI}=$ o.63-1.20). These results were either maintained or further improved at 6-month follow-up (Sahlin et al., 2017), see Table 3. Further, several baseline demographic and clinical variables predicted reductions in NSSI. Among them where young age, higher levels of pre-treatment NSSI frequency, BPD severity, and emotion dysregulation (Sahlin et al., 2018).

\section{Conclusions}

We concluded that ERGT was a potentially feasible and transportable treatment for adult women with NSSI and other self-destructive behaviors and emotion dysregulation when delivered by clinicians in the community (Sahlin et al., 2017).

Table 1. Sociodemographic, clinical, and diagnostic data of the samples in Study I $(N=95)$, Study $2(N=17)$, and Study $3(N=25)$.

\begin{tabular}{|c|c|c|c|}
\hline & $\begin{array}{l}\text { Study I } \\
\text { ERGT }\end{array}$ & $\begin{array}{l}\text { Study II } \\
\text { ERITA F2F }\end{array}$ & $\begin{array}{l}\text { Study III } \\
\text { ERITA Online }\end{array}$ \\
\hline Mean age in years $(S D)$ & $25.1(7.0)$ & $15.31(13.9)$ & $15.7(1.3)$ \\
\hline \multicolumn{4}{|l|}{ Gender } \\
\hline Female & 95 (100\%) & $17(100 \%)$ & $19(76 \%)$ \\
\hline Male & $0(0 \%)$ & $0(0 \%)$ & $1(4 \%)$ \\
\hline Non-binary & $0(0 \%)$ & $0(0 \%)$ & $5(20 \%)$ \\
\hline$n$ meeting full diagnostic criteria for BPD & $65(68 \%)$ & $7(41 \%)$ & $5(20 \%)$ \\
\hline Mean number of BPD criteria & $5.2(1.5)$ & $3.8(1.4)$ & $3.2(1.6)$ \\
\hline Mean NSSI frequency past 6 months (SD) & $61.4(83.3)$ & NA & NA \\
\hline Median NSSI frequency past 12 months (IQR) & NA & $110(8,390)$ & $103(25,197)$ \\
\hline
\end{tabular}

Note BPD = Borderline personality disorder; ERGT = Emotion regulation group therapy; ERITA = Emotion regulation individual therapy;

F2F = Face-to-face; IQR = Interquartile range 


\section{Study II: Development, Feasibility, and Utility of ERITA}

As shown in Study I, ERGT might have clinical utility for NSSI among adults. ERGT had however never been evaluated for adolescents. The aim of Study II was to examine the acceptability and utility of ERITA.

\section{Method}

Study II used an uncontrolled open trial design, conduced within regular child and adolescent mental health service. More information about study methods and results are described by Bjureberg (2018) and Biureberg et al. (2017).

\section{Participants}

Seventeen girls (aged 13-17) with NSSI disorder and their parents were included in the trial. Demographic data is presented in Table 1.

\section{Instruments}

CES (Borkovec \& Nau, 1972) were administered at the end of the first session. The 6 item Working Alliance Inventory - Short Form (WAI-6) (Hedman et al., 2014) was administered after session 3 to measure aspects of the therapeutic alliance (range 6-42). The 9-item Deliberate Self-Harm Inventory (DSHI-9) (Bjärehed \& Lundh, 2008) was used to assess NSSI frequency and versatility. Both DSHI-9 and DERS were administered pre-treatment, post-treatment, and at 6-month follow-up. Additionally, the DSHI-9 and the 16-item version of the DERS (DERS-16) (Bjureberg et al., 2016) were administered weekly during treatment.

\section{Intervention}

ERITA was delivered as an individual treatment, as opposed to the group format utilized in ERGT, because of safety concerns (for a detailed discussion, see Bjureberg, 2018). We also shortened the treatment protocol in order to fit in one school semester resulting in a total of twelve sessions á $45^{-60}$ minutes per session. ERITA was made more youth friendly by changing the design of treatment materials and examples illustrating skills use. Finally, we included a parent program because analyses across treatment studies indicate that a family component is beneficial in treatment of adolescents with NSSI (Glenn et al., 2019; Iyengar et al., 2018; Ougrin et al., 2015). We developed the parent program as an online program with online therapist support. The parent program included seven online modules encompassing information about NSSI and other destructive behaviors, effective communication skills (e.g. validation), emotional awareness, and strategies to increase healthy adaptive activities, conflict management, and problem solving. To ensure full transparency between adolescents, parents, and therapists about the adolescent's health condition, the therapists developed pre-treatment agreements between parent(s) and adolescent, including how and under what circumstances information about the adolescent was to be shared between the parties. Prior to treatment start, we also developed a tailored safety system around the patient and family, including weekly assessments of NSSI and suicidal ideation as well as a detailed crisis plan.

\section{Statistical Analyses}

NSSI frequency was analysed adopting generalized estimation equation (GEE) using a negative binomial distribution with a log link function. Percentage change and NSSI abstinence were calculated by the same methods used in Study I. GEE models with a normal distribution and Cohen's d were used to analyse the continues outcomes.

\section{Results}

Participants rated the treatment as credible, and treatment attendance and ratings of therapeutic alliance were strong (see Table 2). At post-treatment, intentionto-treat analysis revealed significant reductions in past-month NSSI abstinence $(p=0.031), 42 \%(95 \% \mathrm{CI}=$ $8-64)$, a reduction in past-month NSSI frequency as well

Table 2. A summary of main treatment feasibility and acceptance outcome variables in Study I, Study 2, and Study 3.

\begin{tabular}{|c|c|c|c|}
\hline Outcome & $\begin{array}{l}\text { Study I } \\
\text { ERGT }\end{array}$ & $\begin{array}{l}\text { Study II } \\
\text { ERITA F2F }\end{array}$ & $\begin{array}{l}\text { Study III } \\
\text { ERITA Online }\end{array}$ \\
\hline Average number of attended sessions/modules $(S D)$; percentage* & $11.0(5.2) ; 68.8 \%$ & $10.3(3.4) ; 85.8 \%$ & $9.7(2.1) ; 88.2 \%$ \\
\hline Mean treatment credibility $(S D)$ & $5.7(1.8)$ & $6.1(2.1)$ & $6.5(1.1)$ \\
\hline Treatment expectancy (SD) & $47 \%(25.5)$ & $56.43 \%(22.74)$ & $55.6 \%(21.4)$ \\
\hline Therapeutic alliance** & NA & $5.4(1.7)$ & $5.0(1.3)$ \\
\hline Treatment satisfaction & NA & NA & $17.3(4.6)$ \\
\hline
\end{tabular}


as moderate reductions in past-month NSSI versatility $(d=0.50,95 \%$ CI $=0.07-0.78)$. We further detected a $44 \%$ (95\% CI=5-67) reduction in self-destructive behaviors, and large within-group effect sizes in emotion dysregulation $\left(d=0.81,95 \% C I=0.23^{-1.50}\right)$ and global functioning $(d=1.08,95 \% \mathrm{CI}=0.51-1.62)$. These improvements were either maintained or further improved upon at 6-month follow-up (see Table 3). Finally, reductions in emotion dysregulation mediated the NSSI reductions during the course of treatment $(a b=-0.02, \mathrm{SE}=0.01, p=.046)$.

\section{Conclusion}

We concluded that the results provided preliminary support for the acceptability, feasibility, and utility of ERITA for youth with NSSI disorder and reductions in emotion dysregulation was a potential mediator of treatment effect (Bjureberg et al., 2017).

Table 3. A summary of main treatment utility outcome variables in Study I, Study 2, and Study 3 at pre-treatment, post-treatment, and 6-month follow-up.

\begin{tabular}{|c|c|c|c|c|c|}
\hline Measure & Pre-treatment & Post-treatment & 6-month & Pre to post & Pre to 6-moth \\
\hline $\begin{array}{l}\text { Count outcome } \\
\text { Study }\end{array}$ & Median (IQR) & Median (IQR) & Median (IQR) & $\%$ change $[95 \% \mathrm{Cl}]$ & $\%$ change $[95 \% \mathrm{Cl}]$ \\
\hline \multicolumn{6}{|l|}{ NSSI Frequency: DSHI } \\
\hline Study I ERGT & $22(10,56)$ & $10(3,46)$ & $4(0,13)$ & $52[33,66]$ & $76[65,83]$ \\
\hline \multicolumn{6}{|l|}{ NSSI Frequency: DSHI-9 } \\
\hline Study II F2F ERITA & $8(4,13)$ & $2.5(0,4.25)$ & $0(0,3)$ & $42[8,64]$ & $79[60,89]$ \\
\hline \multirow[t]{2}{*}{ Study III Online ERITA } & $9(3,15)$ & $2(0,8)$ & $1(0,6)$ & $55[29,72]$ & $69[45,83]$ \\
\hline & Proportion & Proportion & Proportion & p-value & p-value \\
\hline \multicolumn{6}{|l|}{ NSSI Abstinence: DSHI } \\
\hline Study I ERGT & $4.2 \%$ & $17.9 \%$ & $25.3 \%$ & $<.001$ & $<.001$ \\
\hline \multicolumn{6}{|l|}{ NSSI Abstinence: DSHI-9 } \\
\hline Study II F2F ERITA & $0 \%$ & $29 \%$ & $53 \%$ & .031 & $<.001$ \\
\hline Study III Online ERITA & $0 \%$ & $28 \%$ & $40 \%$ & .007 & $<.001$ \\
\hline $\begin{array}{l}\text { Continuous outcome } \\
\text { Study }\end{array}$ & Mean (sd) & Mean (sd) & Mean (sd) & Cohen's d [95\% Cl] & Cohen's d $[95 \% \mathrm{Cl}]$ \\
\hline \multicolumn{6}{|l|}{ NSSI Versatility: DSHI } \\
\hline Study I ERGT & $3.0(1.8)$ & $2.2(2.0)$ & $1.7(1.8)$ & $0.41[0.20,0.63]$ & $0.65[0.40,0.89]$ \\
\hline \multicolumn{6}{|l|}{ NSSI Versatility: DSHI-9 } \\
\hline Study II F2F ERITA & $2.1(1.5)$ & $1.4(1.2)$ & $0.8(1.0)$ & $0.50[0.07,0.78]$ & $0.89[0.47,1.23]$ \\
\hline Study III Online ERITA & $2.2(1.2)$ & $1.4(1.3)$ & $0.9(1.0)$ & $0.63[0.54,0.77]$ & $1.11[0.96,1.35]$ \\
\hline \multicolumn{6}{|l|}{ Emotion Regulation: DERS } \\
\hline Study I ERGT & $126.0(19.4)$ & $108.2(27.5)$ & $104.7(27.4)$ & $0.91[0.63,1.20]$ & $1.03[0.69,1.38]$ \\
\hline Study II F2F ERITA & $122.7(17.2)$ & $109.7(25.2)$ & $100.6(17.9)$ & $0.81[0.23,1.50]$ & $1.40[0.87,2.03]$ \\
\hline Study III Online ERITA & $125.6(20.1)$ & $110.6(27.2)$ & $99.7(26.8)$ & $0.75[0.59,0.90]$ & $1.20[0.95,1.44]$ \\
\hline
\end{tabular}

Note. $\mathrm{Cl}$ = Confidence intervals; DERS = Difficulties in Emotion Regulation Scale; DSHI = Deliberate Self-Harm Inventory - Full length version; DSHI-9 = Deliberate Self-Harm Inventory - 9 item version; ERGT = Emotion regulation group therapy; ERITA = Emotion regulation individual therapy; F2F = Face-to-face; IQR = Interquartile range. 


\section{Study III: Development, feasibility, and utility of online ERITA}

The aim of the current research program was to develop novel, targeted, and effective interventions that could be easily and widely implemented at a low cost. Guided internet-based CBT (ICBT) has been shown to be effective for several mental disorders (for a review, see Vigerland et al., 2016). Guided ICBT is based on online self-help material and includes guidance and support by a designated therapist communicating through the online platform (Andersson et al., 2019). No therapist-guided online treatments have so far been rigorously evaluated for NSSI (Arshad et al., 2019), and it has been considered a research priority to adapting in-person interventions for self-injury into internet-based formats (Glenn et al., 2019). The main advantages of online treatment compared to in-person therapy include the potential of increased access to evidence-based interventions by eliminating effects of geographical distance between therapist and patient while allowing for less therapist time per patient

(Andersson et al., 2019). Furthermore, individuals with stigmatizing disorders and behaviors may be more likely to use the internet than traditional health care to seek help (Berger et al., 2005; Frost \& Casey, 2016), indicating that online treatment may be particularly useful for individuals with NSSI. Thus, as the next step in our research program, we developed and evaluated an online version of ERITA. The aim of Study III was to examine the feasibility, acceptability, and utility of an online ERITA.

\section{Method}

This study used an uncontrolled open trial design. Please see Bjureberg (2018) and Bjureberg and colleagues (2018b) for a more detailed description of study methods and results.
Figure 1. Screenshots of treatment module overview, interactive scripts, and psychoeducative animations and texts in online ERITA. Reprinted with permission of Springer Nature.
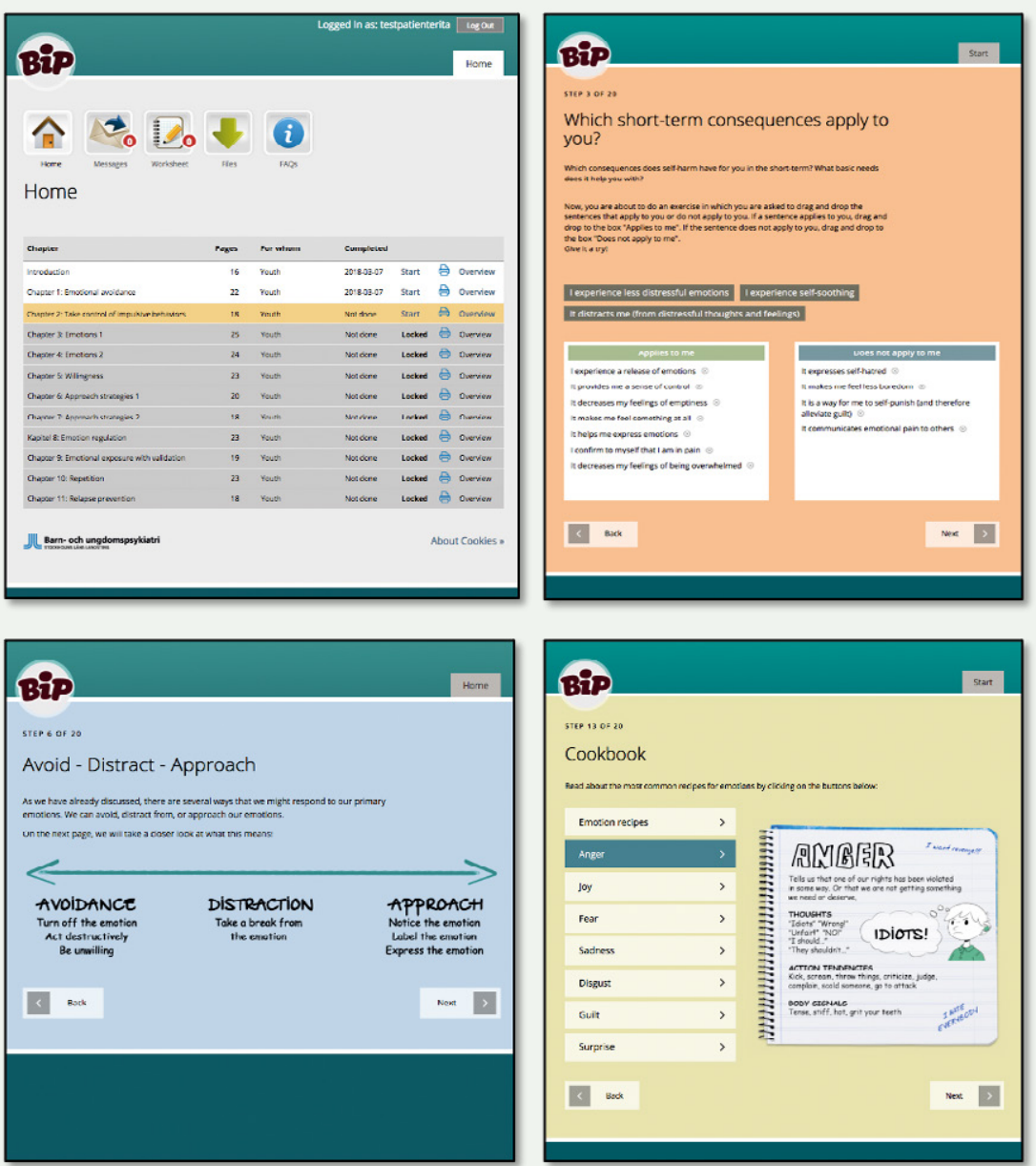


\section{Participants}

In total, 25 adolescents (19 girls, 1 boy, 5 non-binary) aged $13-17(m=15.7, s d=1.3)$ with NSSI disorder and their parents were enrolled in the study. See Table 1 for demographic data.

\section{Instruments}

The CES (Borkovec \& Nau, 1972) were administered at the end of the first session. The revised 12 item WAI (WAI-12; range 12-84) (Hatcher \& Gillaspy, 2006) was administered after session 3. The DSHI-9 (Bjärehed \& Lundh, 2008) and DERS (Gratz \& Roemer, 2004) were administered pre-treatment, post-treatment, and at 6-month follow-up. The DSHI-9 and DERS-16 (Bjureberg et al., 2016) were administered weekly during treatment.

\section{Intervention}

Online ERITA is entirely web-based including 11 modules for the adolescent and 6 modules for the parents delivered over the course of twelve weeks. The modules include texts, animations, and interactive scripts (see Figure 1). A licensed psychologist had regular online contact with both adolescent and parent (separately) via a message function in the platform. The therapist reinforced treatment engagement, answered questions, assisted in planning of and reviewing homework assignments, and problem solved when necessary (see Figure 2). We developed a mobile app to complement the adolescents' online treatment modules. The participants used the app to register self-destructive behaviors, impulses to act destructively, and potential protective factors, on a daily basis. The app also included several programs that could be used to practice skills taught in the online modules, reminders of homework assignments, and an individualized crisis plan (see Figure 3).

\section{Statistical Analyses}

Outcomes were analysed using the same statistical analyses as in Study II.

\section{Results}

Participants rated credibility, expectancy, and satisfaction with the treatment as acceptable, and the therapeutic alliance and treatment completion rate were high (see Table 2). Post-treatment intention-totreat analyses revealed a statistically significant increase in past-month NSSI abstinence ( $p=.007), 55 \%$ (95\% CI = 29-72), reductions in past-month NSSI frequency, moderate reductions in NSSI versatility $(d=0.63,95 \% \mathrm{CI}=$ $0.54^{-0.77)}$, large improvements in global functioning $(d=1.01,95 \% C I=0.77-1.32)$, and moderate improve-

Figure 2. Screenshots of the message functions in online ERITA. Reprinted from Bjureberg's (2018) doctoral thesis from Karolinska Institutet.

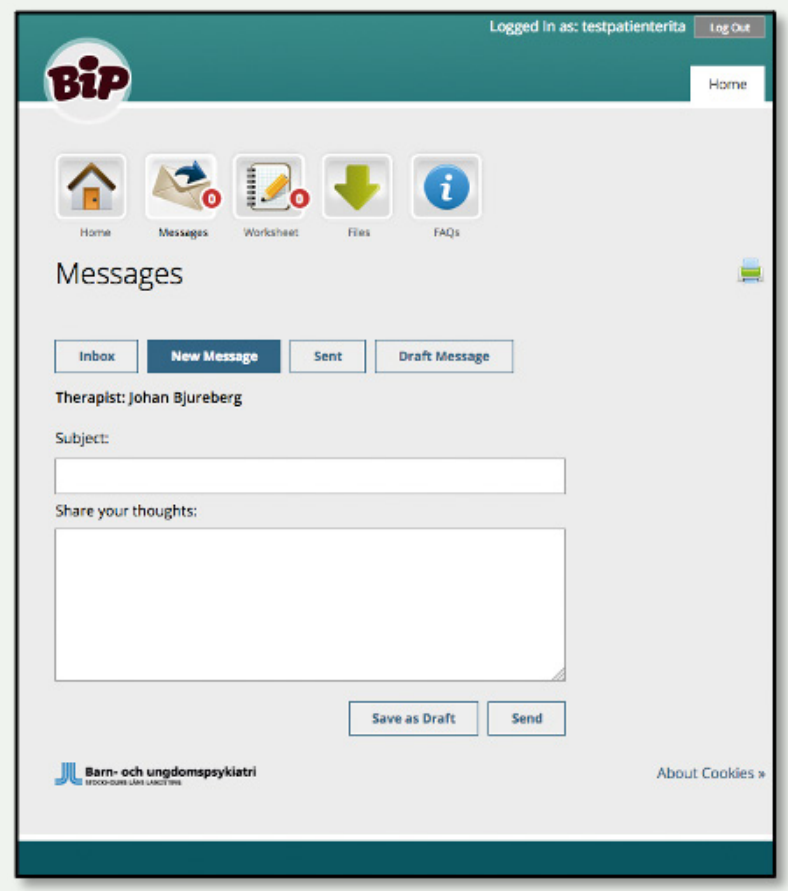

Worksheet
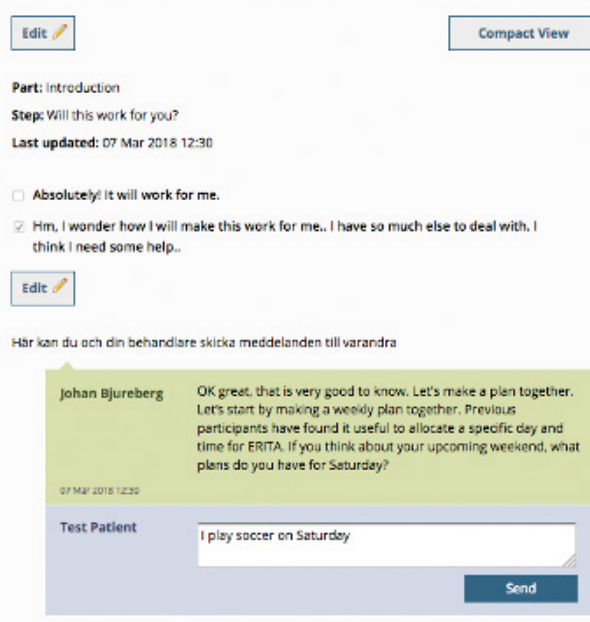
ments in difficulties in emotion regulation $(d=0.75$, 95\% CI $=0.59-0.90)$. These improvements were further strengthened at 3-month follow-up and maintained at 6-month follow-up (see Table 3). Analyses also showed that the online therapist-guided parent program was associated with small to large ( $d s=0.47-1.22)$ improvements in adaptive parent behaviors. Further, change in difficulties in emotion regulation mediated reductions in both NSSI frequency ( $a b=-0.019 ; 95 \% \mathrm{CI}=-0.045^{-}$ -0.003) and self-destructive behaviors ( $a b=0.011 ; 95 \%$ $\mathrm{CI}=0.025^{-0.001)}$ over the course of treatment. Mean therapist time per treated adolescent and parent was $238.5(S D=115.4)$ minutes and $93.9(S D=44.2)$ minutes, respectively.

\section{Conclusion}

We concluded that online ERITA is a potentially acceptable and feasible treatment for adolescents with NSSI disorder (Bjureberg et al., 2018b). These findings were consistent with qualitative analyses based on interviews with the adolescent and parent participants in the treatment, suggesting that the many means of support, both from the app, fictional characters in the online modules, and the online therapist, contributed to improvements in NSSI and related distress (Simonsson et al., 2018).

Figure 3. Screenshot of mobile app from online ERITA. Reprinted with permission from Springer Nature.

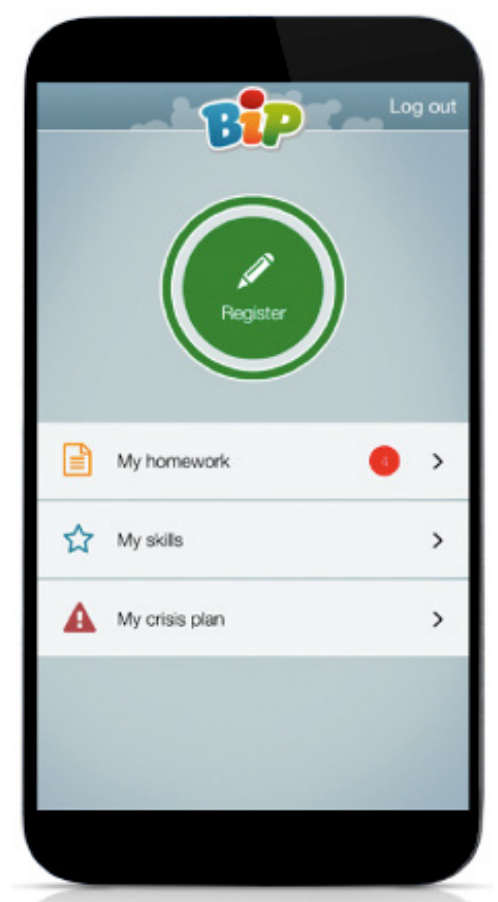

\section{Discussion}

ERGT, when implemented in Swedish regular psychiatric care, delivered by community clinicians appears to be a feasible and useful treatment for NSSI among adult women. Our study of ERITA demonstrates feasibility, acceptability, and utility in the treatment of NSSI among adolescents with NSSI disorder. Online ERITA is also an acceptable, feasible, and promising low-intensity treatment for adolescents with NSSI disorder. Finally, emotion dysregulation mediated week-to-week improvements in NSSI and risk behaviors in ERITA, providing preliminary support for the underlying theory of the treatment.

All three studies were conducted within clinical care under real-world conditions and patients, providing preliminary support for the generalizability and transportability of these treatments. These types of studies may play an important role in increasing the availability of evidence-based treatments for NSSI. Prior to the Swedish ERGT-study, few Swedish psychologists had any previous experience of ERGT. Since this study was conducted, we have organized several workshops and trained more than 120 therapists and several supervisors in ERGT throughout Sweden. The strong interest in disseminating ERGT within health care in Sweden is probably in part due to its promising effects and funding from the National Self-Injury Project, but also due to its relative brevity compared to alternatives (e.g. DBT). There is indeed a need of shorter interventions that specifically target NSSI. Many never seek treatment within health care, so if an individual decides to do so, treatment should be easily accessible and available without delay (Lindgren et al., 2017). However, health care politicians that advocate for short treatments must be reminded of the empirical status of new treatments. ERGT/ERITA could be potentially important complements to treatment as usual; however, RCTs are urgently needed before these novel treatments can substitute well-known alternatives, since the uncontrolled designs employed in Studies I to III cannot answer the question whether these treatments are efficacious. Further, there is likely no one-size-fits-all treatments and longer more comprehensive treatment programs should receive adequate funding to treat those most at risk.

Both in-person ERITA and online ERITA shows promise. Importantly, the mean therapist time per adolescent in the online ERITA trial was approximately one third of the time required in in-person ERITA (or any other brief treatment for NSSI). Thus, online ERITA is promising as an acceptable and potentially effective intervention that could easily be implemented in areas without viable treatment options and for adolescents who would not engage in treatment otherwise, while saving recourses for the clinics. Findings from the online ERITA study raises questions about the relevance of in-person therapist contact in the treatment of adolescent NSSI. In addition to the aforementioned positive 
aspects of online treatments, I want to expand on a few additional potential advantages inherent to the online format. After watching video recordings of both my own and other therapists' in-person therapy sessions, it is sometimes apparent that the patient is not "mentally present" during the session, without the therapist noticing this. Some patients are so occupied with something that happened before the session or with how they are being perceived that it competes with being attentive on learning new skills. Indeed, it is welldocumented that patients usually have poor memory of treatment session content, which is associated with worse treatment outcome (Lee et al., 2020). Further, in-person treatments often suffer from therapist drift (i.e. clinicians' failure to adhere to treatment protocol), which is a well-studied and common barrier to effective treatment delivery (Waller \& Turner, 2016). Finally, although strong therapeutic in-person alliance may be helpful (Mehlum, 2020), the in-person therapist contact (e.g. in the case of bad personal matching between patient and therapist) may also interfere with therapy, especially for individuals (patients and therapists) with interpersonal difficulties. In online therapy, however, all session content (including communication between patient and therapist) is stored online and can always be revisited, and the patient may choose to interact with the treatment material once they are in the right state of mind. Further, online treatment is highly structured and the personal contact is limited to written text which decrease risk of therapist-drift and ineffective therapist-patient communication. Moreover, previous research has indicated that therapists' use of validating strategies facilitates emotion regulation (Carson-Wong et al., 2018) and strong therapeutic alliance has been associated with greater reductions in self-injurious behaviors (Bedics et al., 2015). This may be one aspect in-person therapy that is lost in internet-delivered therapy. Although future research should investigate differences between therapeutic relationship in in-person and online therapy, there is preliminary evidence suggesting that therapeutic alliance is important also in online treatments (Pihlaja et al., 2018). Accordingly, it is encouraging that ratings of therapeutic alliance were similar across Study II and Study III in the present research program. All said, however, there is probably no one-size-fits-all, and while online treatments may be a good treatment alternative for some, others probably need in-person contact to develop trust and practice new skills.

\section{Future directions}

The uncontrolled open trial design used in the aforementioned studies precludes any conclusions regarding causal inferences of potential treatment effects. These findings have, however, provided important information about treatment and study procedure acceptability and feasibility that we have used to inform future RCTs.
One recent extension of this work is our ongoing, fourth study, comparing online ERITA with enhanced treatment as usual in a Swedish national multi-center RCT. We have just completed the recruitment of 166 families to this trial. Our aim is to study the efficacy of the treatment, but also addresses questions concerning potential competing mediators, moderators, and cost-effectiveness consideration. Likewise, a large RCT $(\mathrm{N}=440)$ comparing online ERITA to weekly journaling has just been launched in Denmark. If efficacy can be established in these trials, we are preparing for a fifth and final nation-wide implementation study of online ERITA, delivered within ordinary child and adolescent mental health clinics.

\section{Acknowledgements}

The author wishes to thank all patients and study therapists that have made this research program possible. He also wants to acknowledge his mentors and collaborators Drs Brjánn Ljótsson, Clara Hellner, Erik Hedman-Lagerlöf, Jussi Jokinen, Hanna Sahlin, Lars-Gunnar Lundh, Jonas Bjärehed, Olivia Simonsson, Kim Gratz, and Matthew Tull. Dr. Bjureberg was supported by The Wallenberg Foundation Postdoctoral Scholarship Program at Stanford (KAW 2018.0426). This research program was supported by the National Self Harm project in Sweden, Stockholm County Council regional research grant (SLL20140428), Markus and Amelia Wallenberg Foundation (MAW 2014.0021), Fredrik och Ingrid Thurings Stifelse, Kempe-Carlgrenska Foundation, Bror-Gadelius minnesfod, Clas Groschinskys minnesfod (SF18121).

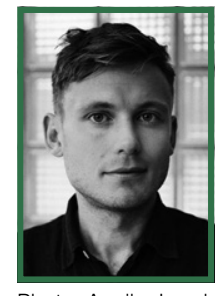

Photo: Annika Lund
JOHAN BJUREBERG PhD is a clinical psychologist and postdoctoral fellow at the Department of Psychology, Stanford University. Johan earned his $\mathrm{PhD}$ from the Department of Psychology, Karolinska Institutet, Sweden, in 2018. Johan's main research area concerns maladaptive behaviors, such as NSSI and aggression, theorized - at least in part - to arise from emotion dysregulation. He studies these behaviors and emotion regulation from a epidemiological, experimental, and psychotherapeutic perspective. 


\section{REFERENCES}

Andersson, G., Titov, N., Dear, B. F., Rozental, A., \& Carlbring, P. (2019) Internet-delivered psychological treatments: from innovation to implementation. World Psychiatry: Official Journal of the World Psychiatric Association (WPA), 18(1), 20-28.

Arshad, U., Farhat-ul-Ain, Gauntlett, I., Husain, N., Chaudhry, N., \& Taylor, P. I. (2019). A Systematic Review of the Evidence Supporting Mobile- and Internet-Based Psychological Interventions For Self-Harm. Suicide \& LifeThreatening Behavior, 50(1), 151-179.

Asarnow, I. R., \& Mehlum, L. (2019). Practitioner Review: Treatment for suicidal and self-harming adolescents - advances in suicide prevention care. Journal of Child Psychology and Psychiatry, and Allied Disciplines, $60(10), 1046-1054$

Asarnow, I. R., Porta, G., Spirito, A., Emslie, G., Clarke, G., ... Brent, D. A. (2011). Suicide attempts and nonsuicidal self-injury in the treatment of resis tant depression in adolescents: findings from the TORDIA study. Journal of the American Academy of Child \& Adolescent Psychiatry, 5o(8), 772-781.

Bedics, I. D., Atkins, D. C., Harned, M. S., \& Linehan, M. M. (2015). The therapeutic alliance as a predictor of outcome in dialectical behavior therapy versus nonbehavioral psychotherapy by experts for borderline personality disorder. Psychotherapy, 52(1), 67-77.

Berger, M., Wagner, T. H., \& Baker, L. C. (2005). Internet use and stigmatized illness. Social Science \& Medicine (1982), 61(8), 1821-1827.

Biärehed, I., \& Lundh, L.-G. (2008). Deliberate Self-Harm in 14-YearOld Adolescents: How Frequent Is It, and How Is It Associated with Psychopathology, Relationship Variables, and Styles of Emotional Regulation? Cognitive Behaviour Therapy, 37(1), 26-37.

Bjureberg, I. (2018). Nonsuicidal self-injury and emotion regulation: clinical correlates and novel treatments. (Doctoral thesis, Karolinska Institutet, Stockholm). Retrieved from https://openarchive.ki.se/xmlui/ handle/10616/46237

Biureberg, I., Ljótsson, B., Tull, M. T., Hedman, E., Sahlin, H., Lundh, L. -G., Gratz, K. L. (2016). Development and validation of a brief version of the difficulties in emotion regulation scale: the DERS-16. Journal of Psychopathology and Behavioral Assessment, 38(2), 284-296.

Biureberg, I., Ohlis, A., Liótsson, B., D'Onofrio, B. M., Hedman-Lagerlöf, E., Jokinen, I., ... Hellner, C. (2018a). Adolescent self-harm with and without suicidality: cross-sectional and longitudinal analyses of a Swedish regional register. Journal of Child Psychology and Psychiatry, 6o(3), 295-304.

Biureberg, I., Sahlin, H., Hedman-Lagerlöf, E., Gratz, K. L., Tull, M. T., Jokinen, I., Hellner, C., \& Ljótsson, B. (2018b). Extending research on Emotion Regulation Individual Therapy for Adolescents (ERITA) with nonsuicidal self-injury disorder: open pilot trial and mediation analysis of a novel online version. BMC Psychiatry, 18(1), 1-13.

Biureberg, I., Sahlin, H., Hellner, C., Hedman-Lagerlöf, E., Gratz, K. L., Biärehed, I., ... Ljótsson, B. (2017). Emotion regulation individual therapy for adolescents with nonsuicidal self-injury disorder: a feasibility study. BMC Psychiatry, 17(1), 411

Borkovec, T. D., \& Nau, S. D. (1972). Credibility of analogue therapy rationales. Journal of Behavior Therapy and Experimental Psychiatry, 3(4), 257-260.

Carson-Wong, A., Hughes, C. D., \& Rizvi, S. L. (2018). The effect of therapist use of validation strategies on change in client emotion in individual DBT treatment sessions. Personality Disorders: Theory, Research, and Treatment, 9(2), 165-171.

Frost, M., \& Casey, L. (2016). Who Seeks Help Online for Self-Injury? Archives of Suicide Research: Official Journal of the International Academy for Suicide Research, 20(1), 69-79.

Glenn, C. R., Esposito, E. C., Porter, A. C., \& Robinson, D. I. (2019). Evidence Base Update of Psychosocial Treatments for Self-Iniurious Thoughts and Behaviors in Youth. Journal of Clinical Child \& Adolescent Psychology, 48(3), 357-392.
Gratz, K.o L. (2001). Measurement of Deliberate Self-Harm: Preliminary Data on the Deliberate Self-Harm Inventory. Journal of Psychopathology and Behavioral Assessment, 23(4), 253-263.

Gratz, K. L., \& Roemer, L. (2004). Multidimensional Assessment of Emotion Regulation and Dysregulation: Development, Factor Structure, and Initial Validation of the Difficulties in Emotion Regulation Scale. Journal of Psychopathology and Behavioral Assessment, 26(1), 41-54.

Gratz, K. L., Bjureberg, I., Sahlin, H., \& Tull, M. T. (2019). Emotion regulation group therapy for nonsuicidal self-injury. In I. I. Washburn (Ed.), Nonsuicidal self-injury Advances in research and practice. Routledge.

Gratz, K. L., \& Gunderson, I. G. (2006). Preliminary data on an acceptance-based emotion regulation group intervention for deliberate self-harm among women with borderline personality disorder. Behavior Therapy, $37(1), 25-35$

Gratz, K. L., Tull, M. T., \& Levy, R. (2014). Randomized controlled trial and uncontrolled 9-month follow-up of an adjunctive emotion regulation group therapy for deliberate self-harm among women with borderline personality disorder. Psychological Medicine, 44, 2099-2112.

Hatcher, R. L., \& Gillaspy, I. A. (2006). Development and validation of a revised short version of the working alliance inventory. Psychotherapy Research, 16(1), 12-25.

Hedman, E., Axelsson, E., Gorling, A., Ritzman, C., Ronnheden, M., Alaoui, S. E, ... Liótsson, B. (2014). Internet-delivered exposure-based cognitive-behavioural therapy and behavioural stress management for severe health anxiety: randomised controlled trial. The British Journal of Psychiatry, 205(4), 307-314.

Iyengar, U., Snowden, N., Asarnow, I. R., Moran, P., Tranah, T., \& Ougrin, D. (2018). A Further Look at Therapeutic Interventions for Suicide Attempts and Self-Harm in Adolescents: An Updated Systematic Review of Randomized Controlled Trials. Frontiers in Psychiatry, 9, 583

Lee, I. Y., Dong, L., Gumport, N. B., \& Harvey, A. G. (2020). Establishing the dose of memory support to improve patient memory for treatment and treatment outcome. Iournal of Behavior Therapy and Experimental Psychiatry, 68,101526 .

Lindgren, B.-M., Svedin, C. G., \& Werkö, S. (2017). A Systematic Literature Review of Experiences of Professional Care and Support Among People Who Self-Harm. Archives of Suicide Research, 22(2), 173-192.

McCauley, E., Berk, M. S., Asarnow, I. R., Adrian, M., Cohen, I., Korslund, K.,... Linehan, M. M. (2018). Efficacy of Dialectical Behavior Therapy for Adolescents at High Risk for Suicide. JAMA Psychiatry, 75(8), 777-785.

Mehlum, L. (2020). Mechanisms of change in dialectical behaviour the rapy for people with borderline personality disorder. Current Opinion in Psychology, 37, 89-93.

Mehlum, L., Ramberg, M., Tormoen, A. I., Haga, E., Diep, L. M., Stanley, B. H., ... Grøholt, B. (2016). Dialectical behavior therapy compared with enhanced usual care for adolescents with repeated suicidal and self-harming behavior: Outcomes over a one-year follow-up. Journal of the American Academy of Child and Adolescent Psychiatry, 55(4), 295-300.

Mehlum, L., Tormoen, A. I., Ramberg, M., Haga, E., Diep, L.M., Laberg, S., ... Groholt, B. (2014). Dialectical behavior therapy for adolescents with repeated suicidal and self-harming behavior: A randomized trial. Journal of the American Academy of Child and Adolescent Psychiatry, 53(10), 1082-1091.

Ohlis, A., Biureberg, I., Lichtenstein, P., D’Onofrio, B. M., Fruzzetti, A. E. Cederlöf, M., \& Hellner, C. (2020). Comparison of suicide risk and other outcomes among boys and girls who self-harm. European Child \& Adolescent Psychiatry, 29(12), 1741-1746. https://doi.org/10.1007/s00787o20-01490-y

Ougrin, D., Tranah, T., Stahl, D., Moran, P., \& Asarnow, I. R. (2015). Therapeutic interventions for suicide attempts and self-harm in adolescents: systematic review and meta-analysis. Journal of the American Academy of Child \& Adolescent Psychiatry, 54(2), 97-107.e2. 
Pihlaja, S., Stenberg, I.-H., Joutsenniemi, K., Mehik, H., Ritola, V., \& Ioffe, G. (2018). Therapeutic alliance in guided internet therapy programs for depression and anxiety disorders - A systematic review. Internet Interventions, 11, $1-10$.

Sahlin, H., Biureberg, I., Gratz, K. L., Tull, M. T., Hedman, E., Biärehed, I., ... Hellner, C. (2017). Emotion regulation group therapy for deliberate selfharm: A multi-site evaluation in routine care using an uncontrolled open trial design. BMI Open, 7(10), eo16220.

Sahlin, H., Bjureberg, I., Gratz, K. L., Tull, M. T., Hedman-Lagerlöf, E., Biärehed, I., ... Ljótsson, B. (2018). Predictors of improvement in an opentrial multisite evaluation of emotion regulation group therapy. Cognitive Behaviour Therapy, 48(4), 322-336.

Simonsson, O., Engberg, H., Biureberg, I., Liótsson, B., Stenstils, I., Sahlin, H., \& Hellner, C. (2018). Experiences of an Online Treatment for Adolescents with Nonsuicidal Self-injury and Their Caregivers: Qualitative Study. Manuscript Under Review.

Swannell, S. V., Martin, G. E., Page, A., Hasking, P., \& St John, N. I. (2014). Prevalence of nonsuicidal self-injury in nonclinical samples: systematic review, meta-analysis and meta-regression. Suicide \& Life-Threatening Behavior, 44(3), 273-303.

Vigerland, S., Lenhard, F., Bonnert, M., Lalouni, M., Hedman, E., Ahlen, I., ... Ljótsson, B. (2016). Internet-delivered cognitive behavior therapy for children and adolescents: A systematic review and meta-analysis. Clinical Psychology Review, 50, 1-10.

Waller, G., \& Turner, H. (2016). Therapist drift redux: Why well-meaning clinicians fail to deliver evidence-based therapy, and how to get back on track. Behaviour Research and Therapy, 77, 129-137. 